\title{
Entre justiça e gestão: colaboração interinstitucional na judicialização da saúde
}

\section{Natalia Pires de Vasconcelos 1}

1 Insper Instituto de Ensino e Pesquisa, São Paulo / SP - Brasil

\begin{abstract}
O sistema de justiça faz mais do que apenas "controlar” a legalidade de políticas públicas e sua execução. O caso da judicialização da saúde no Brasil ilustra como juízes/as, advogados/as públicos/as e promotores/as se envolvem cada vez mais ativamente com a gestão da política de saúde. Esse envolvimento resulta na reorganização da gestão pública assumindo as ações judiciais ajuizadas contra a administração do Sistema Único de Saúde (SUS) como um "problema social" que merece respostas organizadas e coordenação interinstitucional. Este artigo descreve tais respostas com base em padrões de colaboração interinstitucional entre atores do sistema de justiça e profissionais da gestão da saúde em 4 estados brasileiros: São Paulo, Rio de Janeiro, Santa Catarina e Rio Grande do Sul. A partir de tipologia de McNamara (2012, 2016), o texto compara os diferentes graus de integração dessas respostas entre órgãos e traça o "perfil" colaborativo do estado em relação à judicialização da saúde.
\end{abstract}

Palavras-chave: judicialização da saúde; colaboração interorganizacional; saúde pública; sistema de justiça.

\section{Entre justicia y gestión: colaboración interinstitucional en la judicialización de la salud}

El sistema de justicia hace más que simplemente "controlar" la legalidad de las políticas públicas y su implementación. El caso de la judicialización de la salud en Brasil ilustra cómo los jueces, los abogados públicos y los fiscales están cada vez más involucrados en la gestión de la política de salud. Esta participación resulta en la reorganización de la gestión pública. Las demandas presentadas contra la administración del Sistema Único de Salud se transforman en un "problema social" que merece respuestas organizadas y coordinación interinstitucional. Este artículo describe esas respuestas con base en estándares de colaboración interinstitucional entre actores del sistema de justicia y gestores de salud pública en cuatro estados brasileños: São Paulo, Río de Janeiro, Santa Catarina y Rio Grande do Sul. Operacionalizando la tipología de McNamara $(2012,2016)$ este estudio compara el grado de integración de las respuestas entre esos organismos y rastrea el "perfil" colaborativo de cada estado en relación con la judicialización de la salud.

Palabras clave: judicialización de la salud; colaboración interorganizacional; salud pública; sistema de justicia.

\section{Between justice and public management: interinstitutional collaboration in health litigation}

The Brazilian justice system does more than simply review the legality of public policies and oversee their implementation. Looking at health litigation in Brazil reveals how judges, public lawyers, and prosecutors are increasingly involved in policy management, as they comprehend that the rising number of lawsuits seeking healthcare treatment requires management and inter-organizational coordination. This article explores this phenomenon by assessing initiatives of inter-institutional collaboration between actors in the justice and healthcare systems in four Brazilian states: São Paulo, Rio de Janeiro, Santa Catarina, and Rio Grande do Sul. By operationalizing the typology developed by McNamara $(2012,2016)$, this study compares the levels of integration in these responses and traces the collaborative "profile" of each state's approach to dealing with health litigation.

Keywords: health litigation; inter-organizational collaboration; public health; justice system. 


\section{AGRADECIMENTOS}

Este artigo é um dos resultados de pesquisa de doutoramento realizada junto $\grave{a}$ Faculdade de Direito da Universidade de São Paulo, com financiamento de bolsa institucional CNPq. Parte da pesquisa deste trabalho também foi conduzida e financiada no âmbito do programa Fox Fellowship da Yale University. $\mathrm{O}$ artigo se beneficiou dos comentários de muitas pessoas ao longo de três anos de revisão e debates. Agradeço a todos/as os entrevistados que cederam seu tempo e agenda para a pesquisa. $\mathrm{E}$ registro meus agradecimentos especiais a Daniel W. L. Wang, Luciano Da Ros, Luiz Duarte de Oliveira, Paula Sue F. de Siqueira, Vanessa Elias de Oliveira, Paulo Furquim de Azevedo, Conrado Hubner Mendes, Rogerio B. Arantes, Sandro Cabral, Marcos Paulo Verissimo, Diego Werneck Arguelhes, Rafael Bellem de Lima, Rudi Rocha de Castro, Jeferson Mariano, Maria Clara Morgulis, Henrique Wang, Vanessa Boarati, e a Thomas Kadri.

\section{INTRODUÇÃO}

As relações entre o sistema de justiça e a administração pública são uma das preocupações mais presentes nos estudos empíricos do direito e da ciência política em todo o mundo. No caso brasileiro, os impactos da judicialização de políticas sociais, como educação e saúde pública, são talvez os temas de maior atenção. A literatura já aponta o Judiciário como ator relevante no ciclo de políticas públicas, mas, em geral, desconsidera os demais atores do sistema de justiça. Além disso, assume que juízes/as atuam somente no controle externo da política, de modo que restaria à administração pública apenas cumprir ou não as decisões judiciais.

O sistema de justiça, contudo, faz mais do que atuar sobre a execução da política pública e seu controle. Este trabalho explora a relação criativa e colaborativa entre o sistema de justiça e a administração pública com base em estudo qualitativo da judicialização da saúde em 4 estados: São Paulo, Santa Catarina, Rio de Janeiro e Rio Grande do Sul. Nesses locais, são mapeadas as respostas institucionais à judicialização, que veio a ser considerada não só um problema social (Dye, 2013) que requer ações estratégicas, gestão e governança, mas um wicked problem que demanda atuação em colaboração.

Algumas respostas estaduais partem unilateralmente da administração pública, que age na tentativa de mitigar os efeitos da judicialização da saúde ou resolver conflitos antes que sejam judicializados. Mas outras têm se organizado em relações colaborativas entre a gestão pública e organizações do sistema de justiça. Mapear essas respostas e seu grau de colaboração é um passo importante para conhecer melhor os vínculos entre Executivo e Justiça e avançar o campo de estudos sobre a judicialização de políticas públicas, especialmente no nível subnacional. 


\section{JUDICIALIZAÇÃO DE POLÍTICAS PÚBLICAS E COLABORAÇÃO INTERORGANIZACIONAL: CONSIDERAÇÕES TEÓRICAS}

A maioria dos estudos sobre "judicialização de políticas públicas" aposta em explicações de tipo command and control, que buscam verificar compliance de determinações do sistema de justiça na atuação da administração pública em políticas específicas (Langford, Rodriguez-Garavito \& Rossi, 2018). Ou seja, na medida em que as decisões de determinada política pública são questionadas perante o Judiciário, os estudos do campo buscam determinar se a gestão pública cumpre ou não a determinação judicial e quais serão os impactos dessa determinação sobre a oferta de um serviço público ou a proteção de um direito. Esses trabalhos se concentram, em especial, na análise de decisões de tribunais constitucionais e avaliam as respostas que "o outro lado" da disputa judicial tem a oferecer. Nessa visão, o Judiciário - e, em geral, os tribunais de cúpula - é tratado como um ator de controle externo que atua quase unicamente sobre a política pública, uma vez que ela veio a ser executada, corrigindo o conteúdo de uma decisão administrativa para casos individuais ou os rumos de uma política depois de sua implementação (Howlet, Ramesh \& Perl, 2009; Kapiszewski \& Taylor, 2013).

Essa visão tradicional da literatura é desafiada por trabalhos que identificam a pluralidade de atores e organizações que compõem o próprio sistema de justiça para além do Judiciário - como Defensorias Públicas, Ministério Público, procuradorias e advocacia privada - e de dentro do próprio Judiciário, como tribunais subnacionais (Da Ros \& Ingram, 2019) e o Conselho Nacional de Justiça (CNJ) (Ramos, Diniz \& Madureira, 2015; Vasconcelos, 2020). Essas organizações detêm, em geral, elevado grau de independência institucional, poder político e ferramentas procedimentais ou processuais para atuar em diferentes momentos do ciclo de políticas públicas (Arantes \& Moreira, 2019; Da Ros, 2014; Kerche, 2007), podendo interferir na formação da agenda de uma política, em seu planejamento e formulação, na implementação e até na avaliação e revisão de decisões governamentais. Assim, a judicialização de políticas públicas não poderia ser vista apenas como uma consequência de decisões judiciais, mas também como resultado da ação, coordenada ou não, de outras instituições que compõem "as engrenagens" do sistema de justiça e o fazem funcionar numa ou noutra direção (Da Ros, 2014).

Além de envolver mais atores do lado do sistema de justiça, a judicialização também envolve uma pluralidade de atores e organizações de dentro da própria administração pública. Numa secretaria estadual de saúde, por exemplo, uma demanda judicial pode requerer o trabalho de setores diferentes, como coordenadorias e assessoria jurídica próximas ao gabinete, o setor de compras, a central de regulação de urgências ou o setor que planeja a assistência farmacêutica estadual (Vasconcelos, 2018). Ainda que menos autônomos que as organizações do sistema de justiça, tais órgãos, em geral, se dedicam a aspectos diferentes da prestação de uma política.

Dentro do fenômeno da judicialização da saúde, Judiciário, defensorias, promotores/as de justiça, advogados/as privados/as, procuradores/as estaduais e diferentes órgãos da administração pública interagem sobre o mesmo tema, milhares de vezes por ano, para responder às mais de 100 mil novas ações ajuizadas todos os anos no país sobre o tema (CNJ, 2019). Esse jogo repetido entre uma pluralidade de atores incentiva comportamentos estratégicos por parte dessas organizações, que passam a se antecipar e estruturar respostas mais complexas que a resolução do conflito individual. A literatura tem demonstrado que a judicialização da saúde estende no tempo as interações entre administração pública e atores do sistema de justiça, o que gera respostas mais permanentes e gerais do que decisões individuais e seu cumprimento caso a caso (Chagas, Provin, Guimarães \& Amaral, 2020; 
CNJ, 2019; Guimarães \& Palheiro, 2015; Vasconcelos, 2018, 2020; Wang, 2015). Uma das respostas possíveis, discutida neste trabalho, é a coordenação de esforços em colaboração.

A literatura sobre colaboração interorganizacional é um ponto de partida teórico útil para compreender os possíveis resultados desse movimento de maior interação no tempo entre atores de diferentes órgãos. Os trabalhos no campo lidam com a difícil tarefa de explicar de forma dinâmica múltiplos caminhos de interação e ação coletiva altamente sensíveis a condições contextuais (Bryson, Crosby \& Stone, 2006). Essa multiplicidade de variáveis explicativas e suas "potenciais combinações em interação dinâmica" (Williams, 2016, p. 26) privilegiam estudos de caso como método de pesquisa, com especial destaque para o trabalho qualitativo.

O surgimento de colaborações estaria associado principalmente a momentos de crescente turbulência (Gray, 1989), quando parece claro aos envolvidos que a atuação isolada não resolverá o problema, dada a sua complexidade ou seu policentrismo (wicked problems) (Gray, 1989). Esses momentos também convidam as organizações a refletirem e acordarem sobre a natureza do problema, os objetivos comuns que adviriam da colaboração e uma possível divisão de tarefas, custos e responsabilidades (Ansell \& Gash, 2007).

Alguns trabalhos procuraram identificar as condições gerais que afetam e determinam colaborações (Williams, 2016). Em geral, é uma literatura com pretensão explicativa, que dá maior ênfase às variáveis independentes da colaboração. Outros trabalhos buscam caracterizar melhor essa variável dependente, preocupando-se não só em criar certa unicidade teórica, como em determinar com precisão o conceito e seus componentes. É o caso de McNamara $(2012,2016)$, que cataloga a literatura para tipificar diferentes formas de interação interorganizacional, organizando-as num contínuo crescente em direção a maior colaboração.

Segundo a autora, em interações definidas como cooperação, os/as "participantes com capacidade para atingir determinados objetivos resolvem trabalhar juntos/as, mas dentro das estruturas já presentes e das políticas já em curso, e com vistas a servir a seus interesses individuais" (McNamara, 2012, p. 391). Assim, não haveria a necessidade de alterações organizacionais relevantes entre as organizações nem modificação em suas missões e planejamento, já que o foco é no melhor trabalho entre indivíduos que "se comunicam informalmente para ajudar um ao outro" (McNamara, 2016, p. 68). Em geral, essas interações também não envolveriam líderes ou o alto escalão de cada organização.

A coordenação, por sua vez, move as constantes interações individuais em direção a posições da organização por atuação coordenada com outras entidades. Caracteriza-se não só por maior formalização, com a assinatura de convênios e termos de cooperação, mas também inicia uma atuação conjunta das organizações em direção a objetivos comuns.

Esses processos de coordenação podem levar à colaboração, definida pela autora como "uma interação entre participantes que trabalham juntos/as para perseguir objetivos complexos a partir de interesses comuns e responsabilidade compartilhada pelas tarefas interconectadas que não podem ser desenvolvidas individualmente" (McNamara, 2012, p. 391). O elemento-chave da colaboração, que a diferencia num contínuo que passa por cooperação e coordenação, é exatamente o trabalho conjunto que borra as fronteiras entre organizações - requer trabalho coordenado e desenvolvido a partir de relações mais próximas, com compartilhamento de recursos, sistemas, informações e pessoal. ${ }^{1}$

\footnotetext{
${ }^{1}$ McNamara apresenta esse contínuo em seu trabalho de 2012, mas acrescenta uma 4a categoria - colaborações obrigatórias - em artigo de 2016. Concordo com a autora em 2012, contudo. A obrigatoriedade, sobretudo envolvendo órgãos públicos, pode ser um traço de toda e qualquer relação interorganizacional.
} 


\section{MÉTODO}

Este artigo compara as estratégias de gestão da judicialização em 4 estados - São Paulo, Rio de Janeiro, Rio Grande do Sul e Santa Catarina -, operacionalizando os conceitos descritos acima com base no levantamento de McNamara (2012, 2016). Esses locais foram escolhidos por serem 4 dos estados com os maiores níveis de judicialização da saúde no país (CNJ, 2019; Tribunal de Contas da União [TCU], 2017) e também os que mais dispõem de estudos sistematizados sobre o perfil de ações judiciais em saúde e seus impactos. Assim, assume-se que profissionais que atuam na gestão pública da saúde e membros/as do sistema de justiça nestes estados têm experiência no enfrentamento unilateral da judicialização, condição para que a enxerguem como um wicked problem. Todas as iniciativas aqui mapeadas foram observadas até dezembro de 2017, com exceção do Programa Ser Saúde, que, até o fim da coleta de dados deste trabalho, se chamava Resolve + Saúde e estava em fase de negociação. A iniciativa foi firmada em fevereiro de 2020 e incorporada ao presente trabalho.

\subsection{Método de Coleta de Informação}

Foram realizadas 27 entrevistas semiestruturadas: $25 \mathrm{com}$ profissionais da gestão da saúde e procuradores/as estaduais dos 4 estados, 1 com um membro/a do Ministério Público Estadual (MPE) de Santa Catarina e 1 com membro/a da Justiça Federal do Rio de Janeiro. As entrevistas foram conduzidas por telefone e em visitas aos órgãos. Todos os setores das secretarias de saúde responsáveis pelo cumprimento e pela gestão de decisões judiciais foram visitados, assim como as procuradorias estaduais. Tais visitas permitiram presenciar muitas das iniciativas descritas neste estudo. ${ }^{2}$ As entrevistadas e os entrevistados foram escolhidos por sua atuação direta com ações judiciais em saúde. A escolha por entrevistar majoritariamente profissionais da gestão e procuradores/as se deu por serem estes os atores que centralizam, em todos os 4 estados, as informações sobre iniciativas de coordenação e resposta a decisões judiciais que passam pela gestão da saúde.

As informações e as falas dos/as entrevistados/as foram trianguladas entre si até que se atingisse saturação em relação a novas informações sobre iniciativas criadas e em curso. As informações obtidas das entrevistas também foram trianguladas com normas jurídicas e termos de cooperação publicados nos diários oficiais dos estados e da união, assim como constantes das bases de dados da administração pública e da justiça; notícias de veículos de comunicação de grande circulação e de comunicação interna oficial, desde que pública; e publicações de órgãos de controle como TCU e CNJ. ${ }^{3}$

Todos/as os/as entrevistados/as permitiram a gravação da entrevista e a utilização de suas falas, inclusive transcritas. O consentimento foi formalizado por termo de consentimento e confidencialidade em todas as entrevistas presenciais e consentimento gravado em todas as por telefone. Apenas a autora deste artigo e uma assistente de pesquisa ouviram as gravações, que permanecem sigilosas. ${ }^{4}$ Todos os nomes foram preservados, apenas divulgando, com consentimento dos/as entrevistados/

\footnotetext{
${ }^{2}$ É uma parte importante do estudo qualitativo conhecer presencialmente as realidades discutidas e narradas. As visitas serviram para a condução da maior parte das entrevistas e permitiram a construção de redes de contatos e a interação informal, fora do gravador, com profissionais da gestão da saúde e da justiça.

${ }^{3}$ Uma lista contendo todas as normas e publicações de comunicação interna utilizadas pela pesquisa consta do Anexo eletrônico. Recuperado de https://drive.google.com/drive/folders/1_5RrAhEKOCw_6uFSrx0s0muI57c_Atjp?usp=sharing

${ }^{4} \mathrm{O}$ modelo de termo de consentimento consta do Anexo eletrônico, cf. n. 3.
} 
as, seus respectivos estados, cargos e órgãos (conferir Anexo). As entrevistas foram conduzidas entre julho e dezembro de 2017, tiveram em média 40 minutos e seguiram um modelo semiestruturado de questionário, no qual 22 questões buscaram mapear os fluxos de trabalho interno do órgão para lidar com a judicialização e os processos de interação com os demais atores da administração pública e do sistema de justiça (conferir Anexo).

\subsection{Método de Análise}

Com as informações coletadas, foram listadas todas as 20 estratégias de resposta à judicialização da saúde identificadas em cada estado - como pode ser observado nos quadros 2 a 5. Como veremos na seção de resultados, essas respostas foram classificadas em 3 grupos: estratégias pré-processuais, processuais e metaprocessuais de enfrentamento da judicialização da saúde, dependendo do momento em que ocorrem.

Para a análise dos diferentes graus de colaboração, as estratégias foram decompostas em 7 de 10 dimensões catalogadas em meio à literatura por McNamara $(2012,2016)$. A autora cataloga 10 dimensões relevantes que moveriam as interações entre órgãos nesse contínuo entre cooperação, passando por coordenação até colaboração. São elas: desenho institucional, formalização do acordo, autonomia organizacional, pessoal, compartilhamento de informações, processos de tomada de decisão, mecanismos para resolução de problemas, alocação de recursos, integração de sistemas e confiança. Por se tratar de um catálogo de dimensões, nem todas estão presentes em todos os estudos revisados pela autora, assim como algumas guardam intrínseca relação entre si.

Desse modo, "resolução de conflitos" e "tomada de decisão" foram agrupadas no presente trabalho como "processos de tomada de decisão" por se tratar de dimensões sobrepostas - tomar decisões pressupõe que conflitos sejam resolvidos numa interação colaborativa. De modo semelhante, foram agrupadas as dimensões "compartilhamento de informações" e "integração de sistemas" como sobrepostas, já que a integração de sistemas é uma versão estável e formalizada do processo de troca de informações.

Por fim, esta pesquisa não tratou da dimensão "confiança", principalmente, por ser de difícil mapeamento no caso das relações discutidas neste trabalho - trata-se de interações que pressupõem litígio judicial, de modo que oposição, conflito e assimetria de poder são questões que estão no nascedouro de muitas dessas relações. ${ }^{5}$ Confiança, nesse cenário, muitas vezes se confunde com discordância e oposição dentro do processo judicial nas falas dos atores.

As 7 dimensões restantes receberam pontuação de 0 a 3 , em que 0 representa a ausência de qualquer característica de colaboração; 1, quando essa dimensão se caracteriza de forma mais próxima ao que se esperaria de uma cooperação; 2, para coordenação; e 3, para colaboração (Quadro 1). Ao fim, uma média simples aponta os scores finais de cada estratégia e de colaboração do estado.

\footnotetext{
${ }^{5}$ No caso de SES e PGE, "confiança” pode ser um ponto tematizado, mas qualquer constatação sobre essa relação não poderia ser comparada com as demais interações. Por exemplo, enquanto é possível definir graus de confiança diferentes para a relação entre profissionais da gestão da saúde e procuradores/as, por estarem "do mesmo lado" do processo judicial, qualquer relação com defensores/as públicos, promotores/as de justiça ou juízes/as já partiria de pontos de desconfiança, dada a posição desses atores no litígio judicial, combinada com assimetria de poder - profissionais da gestão podem ser responsabilizados pessoalmente em litígios judiciais em saúde.
} 


\section{QUADRO 1 VARIÁVEIS E SCORES PARA COOPERAÇÃO, COORDENAÇÃO E COLABORAÇÃO}

\begin{tabular}{|c|c|c|c|c|}
\hline & Score 0 & Score 1 & Score 2 & Score 3 \\
\hline Desenho institucional & $\begin{array}{l}\text { Não há estrutura de } \\
\text { colaboração. }\end{array}$ & $\begin{array}{c}\text { Estrutura de colaboração } \\
\text { unicamente informal. }\end{array}$ & $\begin{array}{l}\text { Estrutura de colaboração } \\
\text { formalizada por termo e } \\
\text { divisão de competências. }\end{array}$ & $\begin{array}{l}\text { Estrutura de colaboração } \\
\text { formalizada, deliberativa e } \\
\text { distinta das organizações } \\
\text { (Comitês, Câmaras, } \\
\text { Conselhos, etc.). }\end{array}$ \\
\hline Formalização dos acordos & $\begin{array}{l}\text { Não há acordo formal ou } \\
\text { informal de colaboração. }\end{array}$ & $\begin{array}{l}\text { Acordo informal de } \\
\text { colaboração. }\end{array}$ & $\begin{array}{l}\text { Acordo formal de } \\
\text { colaboração. }\end{array}$ & $\begin{array}{c}\text { Acordos formais e } \\
\text { informais. }\end{array}$ \\
\hline Autonomia organizacional & $\begin{array}{l}\text { Não há mais de uma } \\
\text { organização envolvida. }\end{array}$ & $\begin{array}{c}\text { Organizações são } \\
\text { completamente } \\
\text { autônomas. }\end{array}$ & $\begin{array}{l}\text { Organizações são } \\
\text { semiautônomas. }\end{array}$ & $\begin{array}{c}\text { Colaboração cria } \\
\text { organizações autônomas } \\
\text { em relação a membros. }\end{array}$ \\
\hline Pessoal & $\begin{array}{l}\text { Não há envolvimento } \\
\text { de pessoal entre } \\
\text { organizações, apenas de } \\
\text { uma organização. }\end{array}$ & $\begin{array}{l}\text { Níveis hierarquicamente } \\
\text { mais baixos da } \\
\text { organização e não } \\
\text { lideranças. }\end{array}$ & $\begin{array}{l}\text { Níveis intermediários e de } \\
\text { supervisão. }\end{array}$ & $\begin{array}{c}\text { Níveis hierarquicamente } \\
\text { mais altos e/ou } \\
\text { lideranças. }\end{array}$ \\
\hline $\begin{array}{l}\text { Compartilhamento de } \\
\text { informações }\end{array}$ & $\begin{array}{l}\text { Organização trabalha } \\
\text { sozinha com as } \\
\text { informações que dispõe. }\end{array}$ & $\begin{array}{l}\text { Compartilhamento de } \\
\text { informações é informal. }\end{array}$ & $\begin{array}{l}\text { Compartilhamento de } \\
\text { informações formalizado } \\
\text { por reuniões e trocas de } \\
\text { pessoal. }\end{array}$ & $\begin{array}{l}\text { Integração de sistemas e } \\
\text { criação de comitês com } \\
\text { acesso à informação a } \\
\text { todos os participes. }\end{array}$ \\
\hline $\begin{array}{l}\text { Processo de tomada de } \\
\text { decisão }\end{array}$ & $\begin{array}{c}\text { Não há interação entre } \\
\text { organizações na tomada } \\
\text { de decisão. }\end{array}$ & $\begin{array}{l}\text { Interação ocorre, mas } \\
\text { tomada de decisão é } \\
\text { independente em cada } \\
\text { órgão. }\end{array}$ & $\begin{array}{c}\text { Tomada de decisão é } \\
\text { centralizada em alguns } \\
\text { atores ou na organização } \\
\text { principal. }\end{array}$ & $\begin{array}{l}\text { Tomada de decisão } \\
\text { coletiva entre todas as } \\
\text { organizações. }\end{array}$ \\
\hline Alocação de Recursos & $\begin{array}{c}\text { Não há interação. A } \\
\text { organização investe } \\
\text { apenas recursos seus em } \\
\text { suas atividades. }\end{array}$ & $\begin{array}{l}\text { Há compartilhamento } \\
\text { apenas de informações. }\end{array}$ & $\begin{array}{l}\text { Recursos físicos e } \\
\text { financeiros podem ser } \\
\text { compartilhados, mas } \\
\text { apenas para interesses } \\
\text { individuais. }\end{array}$ & $\begin{array}{l}\text { Recursos financeiros e } \\
\text { físicos são arrecadados } \\
\text { de todos para objetivos } \\
\text { coletivos. }\end{array}$ \\
\hline
\end{tabular}

Fonte: Elaborado pela autora com base em McNamara $(2012,2016)$.

Atribuir scores a variáveis qualitativas permite comparar as experiências entre si de forma mais direta, resumindo muitas dimensões qualitativas em algumas categorias que podem ser organizadas numa escala de colaboração. ${ }^{6}$

\footnotetext{
${ }^{6}$ Atribuir scores, ou seja, valores artificiais, numa escala, para resumir variáveis complexas do mundo social, é uma técnica de pesquisa empregada em estudos de métodos mistos, a qual busca combinar as potencialidades das pesquisas qualitativas e quantitativas. Esse tipo de trabalho, contudo, tem limitações. Como bem apontado por um dos revisores deste trabalho, existe um grau de subjetividade na construção das categorias que é refletido nos scores. A discussão sobre subjetividade na pesquisa qualitativa é bastante problematizada pela literatura. Conferir, por exemplo: King et al. (2014), Mahoney e Goertz (2006) e Onwuegbuzie e Leech (2005). Para reduzir essa subjetividade, o anexo eletrônico apresenta de forma exaustiva as razões que levaram ao score de cada categoria.
} 


\section{RESULTADOS}

\subsection{Respostas Institucionais à Judicialização}

O perfil da judicialização nos 4 estados é bastante semelhante. Trata-se de ações judiciais de caráter individual que requerem, em sua maioria, medicamentos não padronizados por protocolos clínicos do Sistema Único de Saúde (SUS). As decisões judiciais, tanto em primeira quanto em segunda instância, são largamente favoráveis aos demandantes (Ferraz, 2011; Vasconcelos, 2018). Uma diferença importante, contudo, é o tipo de representação predominante nos estados. Enquanto em São Paulo e em Santa Catarina a maior parte das ações é ajuizada por advogados privados (Chieffi \& Barata, 2009), no Rio Grande do Sul (Biehl, Amon, Socal \& Petryna, 2012) e no Rio de Janeiro a Defensoria Pública é predominante (Ventura, 2012).

As respostas a essa judicialização podem ser agrupadas em 3 grandes momentos ou fases: pré-processuais, ou que procuram evitar a judicialização administrativamente; processuais de defesa e gestão do cumprimento de decisões judiciais; e metaprocessuais, nas quais se desenham medidas gerais de compreensão, gestão ou governança da judicialização em todo o estado. Abaixo, essas estratégias são apresentadas de forma resumida nos Quadros 2, 3, 4 e 5.

\section{QUADRO 2 RESPOSTAS À JUDICIALIZAÇÃO DA SAÚDE EM SÃO PAULO}

\begin{tabular}{|c|c|c|c|c|}
\hline & Estratégia & Forma & $\begin{array}{c}\text { Atores de criação da } \\
\text { política }\end{array}$ & $\begin{array}{c}\text { Atores } \\
\text { implementadores }\end{array}$ \\
\hline $\begin{array}{l}\text { Respostas Pré- } \\
\text { Processuais }\end{array}$ & $\begin{array}{l}\text { Atendimento } \\
\text { administrativo para } \\
\text { medicamentos e } \\
\text { produtos. } \\
\text { Acessa SUS - fase } \\
\text { de triagem nos } \\
\text { Juizados Especiais } \\
\text { e Varas da Fazenda } \\
\text { Pública. }\end{array}$ & $\begin{array}{l}\text { Processo administrativo por meio } \\
\text { de requerimento junto à Comissão } \\
\text { de Farmacologia da SES/SP. } \\
\text { Convênio entre atores. Triagem de } \\
\text { pacientes e tentativa de resolução } \\
\text { administrativa. Atuação de equipe } \\
\text { técnica cedida pela SES-SP no } \\
\text { AME Maria Zélia. }\end{array}$ & $\begin{array}{c}\text { SES-SP, PGE-SP (atuou } \\
\text { no desenho), MP-SP, } \\
\text { DPE, TJ-SP }\end{array}$ & SES-SP, DPE e TJ/SP \\
\hline $\begin{array}{l}\text { Respostas } \\
\text { Processuais }\end{array}$ & $\begin{array}{l}\text { Cumprimento de } \\
\text { decisões judiciais. }\end{array}$ & $\begin{array}{l}\text { Fluxo de cadastro, de análise } \\
\text { do pedido e de compra dos } \\
\text { medicamentos judicializados, } \\
\text { coordenado pela CODES via } \\
\text { S-CODES. } \\
\text { Elaboração de pareceres técnicos } \\
\text { pela CODES em interação com a } \\
\text { PGE-SP (PJ8). Atuação caso a caso } \\
\text { para demandas de grande impacto. } \\
\text { Interação entre SES-SP e PGE-SP } \\
\text { via S-CODES, reuniões semanais, } \\
\text { contato pessoal entre atores. }\end{array}$ & SES-SP e PGE-SP & SES-SP e PGE-SP \\
\hline
\end{tabular}


RAP | Entre justiça e gestão: colaboração interinstitucional na judicialização da saúde

\begin{tabular}{|c|c|c|c|c|}
\hline & Estratégia & Forma & $\begin{array}{l}\text { Atores de criação da } \\
\text { política }\end{array}$ & $\begin{array}{c}\text { Atores } \\
\text { implementadores }\end{array}$ \\
\hline \multirow{3}{*}{$\begin{array}{l}\text { Respostas } \\
\text { Metaprocessuais }\end{array}$} & NAT & $\begin{array}{c}\text { Mediação e elaboração de } \\
\text { pareceres para casos de saúde } \\
\text { suplementar. Alteração recente } \\
\text { para NAT geral. }\end{array}$ & $\begin{array}{l}\text { Inicialmente TJ-SP, ANS, } \\
\text { ABRAMGE, FenaSaúde; } \\
\text { Atualmente: CNJ, } \\
\text { Justiça Estadual e } \\
\text { Federal }\end{array}$ & TJ-SP \\
\hline & $\begin{array}{l}\text { Treinamento e } \\
\text { interlocução com } \\
\text { procuradores/as } \\
\text { e gestores/as do } \\
\text { interior - "casamento } \\
\text { institucional". }\end{array}$ & $\begin{array}{l}\text { Reuniões entre diretores de DRS, } \\
\text { procuradores/as de regionais do } \\
\text { interior, coordenadores da PJ8 e } \\
\text { CODES. }\end{array}$ & SES-SP e PGE-SP & SES-SP e PGE-SP \\
\hline & Comitê Estadual. & $\begin{array}{c}\text { Elaboração de recomendações, } \\
\text { fórum de debates e integração } \\
\text { entre gestores/as e sistema de } \\
\text { justiça. }\end{array}$ & CNJ, JE, JF & $\begin{array}{l}\text { SES, SMS-São Paulo; } \\
\text { PGE-SP; MPE, MPF, } \\
\text { DPE, DPU, AGU, JE, } \\
\text { JF, COSEMS, CRM, } \\
\text { CRF, CRA }\end{array}$ \\
\hline
\end{tabular}

Fonte: Elaborado pela autora.

\section{QUADRO 3 RESPOSTAS À JUDICIALIZAÇÃO DA SAÚDE NO RIO DE JANEIRO}

\begin{tabular}{|c|c|c|c|c|}
\hline & Estratégia & Forma & $\begin{array}{l}\text { Atores - criação } \\
\text { da política }\end{array}$ & Atores implementadores \\
\hline \multirow[t]{2}{*}{$\begin{array}{l}\text { Respostas Pré- } \\
\text { Processuais }\end{array}$} & $\begin{array}{l}\text { Câmara de } \\
\text { Resolução de Litígios } \\
\text { em Saúde. }\end{array}$ & $\begin{array}{c}\text { Triagem administrativa com a } \\
\text { possibilidade de judicialização via } \\
\text { Defensorias, instaladas in loco. }\end{array}$ & $\begin{array}{l}\text { PGE-RJ, } \\
\text { SESDEC-RJ, } \\
\text { DPE, DPU }\end{array}$ & $\begin{array}{c}\text { PGE-RJ, SESDEC-RJ, DPE, } \\
\text { DPU }\end{array}$ \\
\hline & $\begin{array}{l}\text { Cumprimento de } \\
\text { decisões judiciais. }\end{array}$ & $\begin{array}{c}\text { Análise, triagem e cumprimento } \\
\text { realizados por equipe } \\
\text { multidisciplinar da CADJ. }\end{array}$ & SESDEC-RJ & SESDEC-RJ \\
\hline \multirow[t]{2}{*}{$\begin{array}{l}\text { Respostas } \\
\text { Processuais }\end{array}$} & Defesa judicial. & $\begin{array}{l}\text { Pareceres elaborados por equipe } \\
\text { técnica da SESDEC-RJ localizada } \\
\text { dentro da PGE-RJ. }\end{array}$ & $\begin{array}{l}\text { SESDEC-RJ e } \\
\text { PGE-RJ }\end{array}$ & SESDEC-RJ e PGE-RJ \\
\hline & NAT & $\begin{array}{c}\text { Elaboração de pareceres técnicos } \\
\text { para auxílio de magistrados/as. }\end{array}$ & $\begin{array}{l}\text { SESDEC-RJ e } \\
\text { TJ-RJ }\end{array}$ & SESDEC-RJ, JE e JF \\
\hline $\begin{array}{l}\text { Respostas } \\
\text { Meta- } \\
\text { Processuais }\end{array}$ & Comitê Estadual. & $\begin{array}{c}\text { Elaboração de recomendações, } \\
\text { fórum de debates e integração } \\
\text { entre gestores/as e sistema de } \\
\text { justiça. }\end{array}$ & CNJ, JE, JF & $\begin{array}{l}\text { SESDEC-RJ, SMS-RJ, PGE- } \\
\text { RJ, PGM-RJ, MPE, MPF, } \\
\text { DPE, DPU, JE, JF, gestores/ } \\
\text { as de saúde municipais, } \\
\text { membros/as da academia }\end{array}$ \\
\hline
\end{tabular}

Fonte: Elaborado pela autora. 


\section{QUADRO 4 RESPOSTAS À JUDICIALIZAÇÃO DA SAÚDE NO RIO GRANDE DO SUL}

\begin{tabular}{|c|c|c|c|c|}
\hline & Estratégia & Forma & $\begin{array}{l}\text { Atores - criação } \\
\text { da política }\end{array}$ & Atores implementadores \\
\hline $\begin{array}{l}\text { Respostas Pré- } \\
\text { Processuais }\end{array}$ & $\begin{array}{c}\text { Ser Saúde. } \\
\text { Convênio com a } \\
\text { Defensoria Pública. }\end{array}$ & $\begin{array}{c}\text { Defensoria remete usuários às } \\
\text { unidades da SES-RS antes de } \\
\text { propor ação judicial. }\end{array}$ & SES-RS e DPE & SES-RS e DPE \\
\hline Respostas & $\begin{array}{l}\text { Cumprimento de } \\
\text { decisões judiciais. }\end{array}$ & $\begin{array}{l}\text { Convênio com o Poder Judiciário } \\
\text { e PGE para melhorar os fluxos } \\
\text { de comunicação e cumprimento } \\
\text { de decisões via sistema AME. }\end{array}$ & $\begin{array}{c}\text { SES-RS, PGE e } \\
\text { TJRS }\end{array}$ & SES-RS, PGE e TJRS \\
\hline Processuais & Defesa judicial. & $\begin{array}{c}\text { Equipe técnica terceirizada, } \\
\text { contratada pela SES-RS em } \\
\text { parceria com a PGE-RS, para } \\
\text { elaborar pareceres. }\end{array}$ & SES-RS e PGE-RS & PGE-RS \\
\hline $\begin{array}{l}\text { Respostas Meta- } \\
\text { Processuais }\end{array}$ & Comitê Estadual. & $\begin{array}{c}\text { Elaboração de recomendações, } \\
\text { fórum de debates e integração } \\
\text { entre gestores/as e sistema de } \\
\text { justiça. }\end{array}$ & CNJ, JE, JF & $\begin{array}{l}\text { SES-RS, PGE-RS, MPE, MPF, } \\
\text { DPE, JE, JF, Federação das } \\
\text { Associações dos Municípios } \\
\text { do RS (FAMURS), AGU, } \\
\text { CREMERS }\end{array}$ \\
\hline
\end{tabular}

Fonte: Elaborado pela autora.

\section{QUADRO 5 RESPOSTAS À JUDICIALIZAÇÃO DA SAÚDE EM SANTA CATARINA}

\begin{tabular}{|c|c|c|c|c|}
\hline & Estratégia & Forma & $\begin{array}{c}\text { Atores — criação da } \\
\text { política }\end{array}$ & Atores implementadores \\
\hline \multirow[t]{2}{*}{$\begin{array}{c}\text { Respostas Pré- } \\
\text { Processuais }\end{array}$} & NAT & $\begin{array}{l}\text { Sistema de consulta CEOS, aberto } \\
\text { para membros do Judiciário, } \\
\text { Defensorias e Ministério Público. } \\
\text { A consulta por promotores/as e } \\
\text { defensores/as permite evitar ações } \\
\text { judiciais. }\end{array}$ & SES-SC & SES-SC \\
\hline & $\begin{array}{c}\text { Cumprimento } \\
\text { de decisões } \\
\text { judiciais. }\end{array}$ & $\begin{array}{l}\text { Fluxo de cadastro, de análise } \\
\text { do pedido e de compra dos } \\
\text { medicamentos judicializados, } \\
\text { coordenado pela COMAJ e COJUR. }\end{array}$ & SES-SC & SES-SC e PGE-SC \\
\hline $\begin{array}{l}\text { Respostas } \\
\text { Processuais }\end{array}$ & $\begin{array}{l}\text { Defesa } \\
\text { judicial. }\end{array}$ & $\begin{array}{l}\text { Elaboração de pareceres técnicos } \\
\text { pela COMAJ em interação com a } \\
\text { PGE-SC (NARAS). Atuação caso a } \\
\text { caso para demandas de grande } \\
\text { impacto pela COJUR. Interação } \\
\text { entre SES-SC e PGE-SC via PGE- } \\
\text { Net, ofícios e telefone. }\end{array}$ & SES-SC e PGE-SC & SES-SC e PGE-SC \\
\hline
\end{tabular}




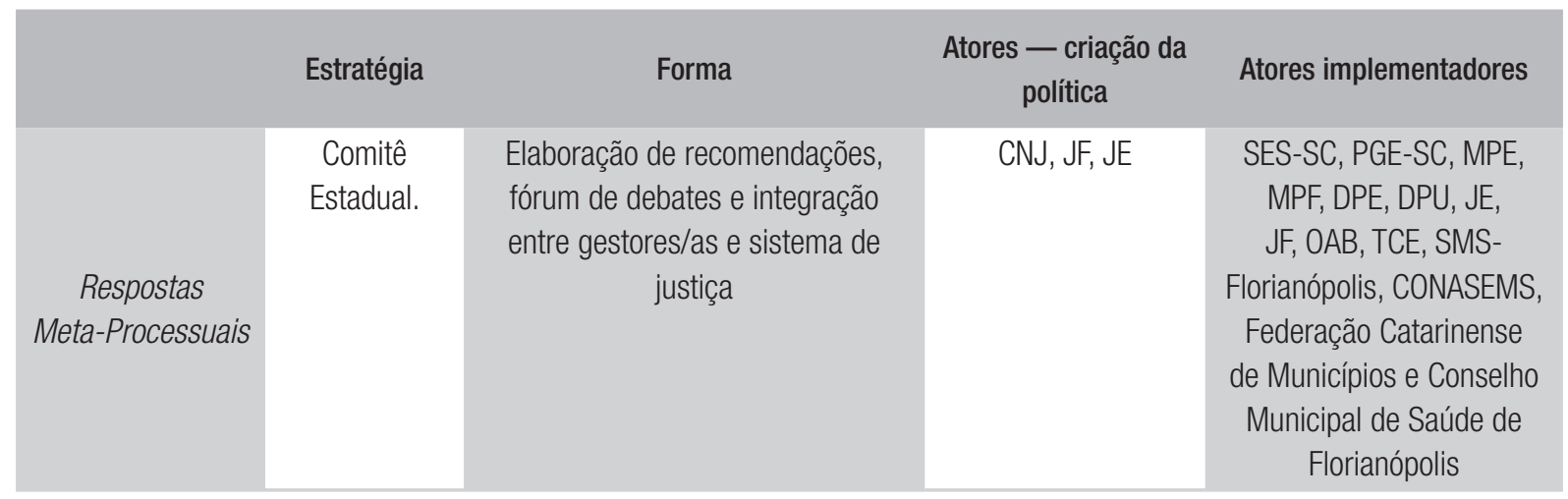

Fonte: Elaborada pela autora.

\subsection{Respostas Pré-Processuais}

As respostas pré-processuais encontradas se dividem em 2 tipos: aquelas em que a Secretaria de Estado de Saúde (SES) atua sozinha na análise de pedidos administrativos por medicamentos, serviços e insumos fora da política, decidindo com base em requisição direta por demandantes; e aquelas organizadas com base em acordos com as Defensorias Públicas - Defensoria Pública do Estado (DPE) e Defensoria Pública da União (DPU) -, nas quais se estabelecem formas de triagem ou de análise de pedidos pelo trabalho conjunto entre defensores/as e profissionais da gestão.

São Paulo adota, por exemplo, as duas estratégias na tentativa de conter tanto a judicialização que viria por meio das defensorias quanto a que advêm de advogados/as privados/as e, por essa razão, descentralizada e de mais difícil controle.

O Acessa SUS parte de um convênio entre a SES, a Procuradoria Geral do Estado (PGE), o Ministério Público Estadual, a DPE e o Tribunal de Justiça (TJ) para a triagem de pacientes e tentativa de resolução administrativa de potenciais demandas. A gestão e o custeio da iniciativa são de responsabilidade da SES-SP, e a atuação da sua equipe técnica ocorre no Ambulatório Médico de Especialidades Maria Zélia, no Bairro do Belenzinho, em São Paulo.

O processo administrativo comum, por sua vez, funciona de forma a concentrar tanto as requisições administrativas comuns da SES quanto pedidos de medicamentos não padronizados, o que em geral não ocorre nos demais estados pela via administrativa.

À semelhança do Acessa SUS, no Rio Grande do Sul, o projeto Ser Saúde estrutura uma triagem administrativa de pedidos que chegam à DPE. Implantado em fevereiro de 2020, o projeto expande convênio que já existia entre a SES e defensores/as públicos/as, mas que funcionava em menor escala no município de Santa Maria. O projeto Ser Saúde não tem espaço próprio de atendimento, como no caso do Acessa SUS e CRLS, funcionando a partir da comunicação entre defensoria e SES caso a caso.

Um projeto semelhante se dá na Câmara de Resolução de Litígios em Saúde no Rio de Janeiro (Guimarães \& Palheiro, 2015; Teixeira 2011; Souza, 2016, 2018). Sua criação formal, em 2012, ${ }^{7}$ alinhou DPE, DPU, PGE, Procuradoria Geral do Município do Rio de Janeiro, SES e Secretarias de Saúde

\footnotetext{
${ }^{7}$ Tanto o Acessa SUS quanto a CRLS e o Ser Saúde se estabelecem com base em tentativas anteriores de cooperação administrativa entre secretarias e defensorias públicas. Para um breve histórico dessa experiência no Rio de Janeiro, confira Teixeira (2011) e Guimarães e Palheiro (2015). Para São Paulo, confira Fanti (2010). Para o Rio Grande do Sul, confira Vasconcelos (2018).
} 
Municipais (SMS). A PGE teve um papel fundamental na criação e na operacionalização do convênio, mediando a negociação entre todos os atores envolvidos e cedendo espaço físico e funcionários. A CRLS funciona no centro do Rio de Janeiro, num prédio desapropriado pela PGE. Também é a PGE que mantém a administração geral do prédio, fornecendo os serviços de limpeza, copa, vigilância e ascensorista.

A Câmara começou a operar em setembro de 2013, e, conforme noticiado pela PGE, já no primeiro ano de atuação solucionou administrativamente $38 \%$ dos casos recebidos, número que subiu para 54\% em 2016, num total de 30 mil pacientes atendidos. Em 2013, a Câmara chegou a atender 50 pacientes por dia, número que subiu a 100 atendimentos em média, por dia, em 2016. No prédio da CRLS, funcionários cedidos por SES, SMS, DPE e DPU prestam atendimento de porta e, em diálogo, resolvem o problema do demandante - quer pela via administrativa, preferível, quer pela judicial. No total, em 2017, trabalhavam na CRLS em torno de 68 funcionários/as, entre servidores/as das secretarias, defensores/as, assessores/as, equipe técnica e estagiários. A equipe técnica da CRLS serve ainda como ponto de contato da secretaria com as regiões de saúde e defensorias no interior, realizando a distância a assessoria técnica administrativa desses órgãos.

\subsection{Respostas Processuais}

Entre as estratégias processuais está a especialização e melhora das defesas técnicas e dos fluxos de cumprimento das demandas judiciais. Dentro das secretarias foram criados órgãos especializados, como o Grupo de Coordenação das Demandas Estratégicas do SUS (Codes), em São Paulo; a Central de Atendimento à Demanda Judicial (CADJ), no Rio de Janeiro; e a Comissão Multidisciplinar de Apoio Judicial (Comaj). Essas estruturas multidisciplinares contratam técnicos próprios para o atendimento de demandas judiciais ou recebem funcionários realocados da própria secretaria para tais funções.

Destaca-se também o papel das PGEs, presentes em quase todas as estratégias implementadas nos 4 estados e principais parceiras das secretarias na defesa e no cumprimento de decisões judiciais. Essa atuação não se resume ao script legal e processual da atuação como advogado no "contencioso ou consultivo"; envolve as PGEs em formas criativas de interação, com compartilhamento de sistemas, desenho de estratégias de gestão conjunta de processos com a SES, otimização da sua comunicação por procedimentos eletrônicos, reuniões regulares e troca de pessoal.

Todos os estados têm unidades especializadas das PGEs para o atendimento de demandas em saúde. Em São Paulo, a Coordenadoria Judicial de Saúde pública da PGE e a Procuradoria Judiciária 8 (PJ-8) organizam a atuação do atendimento de demandas em saúde na capital e no interior. Além disso, há sempre um membro da PGE na consultoria jurídica do próprio gabinete da secretaria de saúde - característica também presente no Rio de Janeiro. A PGE e a SES paulistas enviam regulamente procuradores/as e servidores/as para períodos de estágio mútuo na PJ-8 e no Codes. Ambos os órgãos se comunicam por um sistema on-line de gestão de processos e instrução probatória (S-Codes).

Em Santa Catarina, o Núcleo de Ações Repetitivas à Saúde (Naras) atua em parceria com a SES para elaborar defesas processuais e administrar o cumprimento das decisões judiciais. De forma semelhante, o Rio Grande do Sul conta com 20 procuradores/as especializados/as que procuram concentrar a maior parte das demandas. Para acompanhar o cumprimento e evitar sanções e multas judiciais, a SES e a PGE firmaram parceria com o Tribunal de Justiça Estadual e o Tribunal Regional Federal para que juízes/as possam acessar o sistema de Administração de Medicamentos Especiais 
(AME), que acompanha a demanda e o estoque de medicamentos e insumos. A parceria também fixa compromissos claros sobre prazos para cumprimento e comunicação de decisões em tutela antecipada e sentenças. Além disso, para tornar a defesa da PGE no estado mais técnica e eficiente, a SES-RS mantém convênio com a PGE para a contratação de médicos/as pareceristas, selecionados pela SES, para auxiliar a PGE de forma remota.

No Rio de Janeiro, a PGE-16 concentra a defesa das demandas de saúde da capital, com auxílio de pareceres de membros da SES cedidos à PGE para a elaboração de defesas mais técnicas. Por meio da CADJ, PGE e SES também monitoram o cumprimento de decisões. Além desta atuação mais especializada, a parceria entre PGE e SES foi condição para a criação da CRLS.

Outra iniciativa processual comum aos estados foi a criação de Núcleos de Apoio Técnico (NAT) em Saúde dentro do Judiciário, a fim de apoiar e instruir juízes/as em suas decisões. Os núcleos compõem uma das muitas iniciativas comandadas pelo CNJ para a judicialização da saúde, mas assumem formatos muito distintos de estado para estado. Por exemplo, em Santa Catarina, foi criado como um órgão consultivo para todo o sistema de justiça e funciona dentro da SES, onde funcionários da secretaria alimentam um banco de dados sobre medicamentos e informações do SUS denominado Sistema de Comissão Multidisciplinar de Apoio (Siscomaj-Ceos). No Rio de Janeiro, o NAT funciona em espaços cedidos pela Justiça Federal e Estadual, mas é liderado por funcionários da SES e composto de uma equipe multidisciplinar de mais de 70 funcionários em plantão para auxiliar juízes/as em decisões técnicas.

\subsection{Respostas Metaprocessuais}

Entre as respostas metaprocessuais, destacam-se os Comitês Estaduais de Saúde do CNJ. Recomendados e depois exigidos pelo CNJ, ${ }^{8}$ todas as justiças do país criaram alguma forma de comitê, e, nos quatro estados estudados, eles se tornaram os espaços de articulação do maior número de atores envolvidos com a judicialização. Entrevistados/as do Rio Grande do Sul e do Rio de Janeiro reclamam "autoria" da iniciativa, dizendo que, se passou a ser uma recomendação do CNJ, é porque já era implementado informalmente como medida de sucesso nos dois estados. Em Santa Catarina, o Comitê Estadual de Monitoramento e Resolução das Demandas de Assistência da Saúde de Santa Catarina (Comesc), como denominam a iniciativa, é apontado pelos/as entrevistados/as como o espaço mais produtivo para debater questões sobre judicialização no estado. Em São Paulo, o Comitê somente foi criado em 2017, mas é a entidade que gere e organiza o NAT paulista.

Além do Comitê, São Paulo conta com a cooperação intensa entre PGE e SES na fase metaprocessual. Uma dessas iniciativas é o "casamento institucional", nas palavras dos/as entrevistados/as, no qual a chefia da PJ-8, em parceria com a do Codes, promove, pelo interior do estado, reuniões entre procuradores/as estaduais e diretores/as das regionais de saúde, de modo a alinhar a atuação em demandas judiciais no interior.

${ }^{8}$ Cf. Recomendação CNJ no 31, de 30 de março de 2010, e, posteriormente, Resolução CNJ nº 238, de 6 de setembro de 2016, ambas disponíveis em https://atos.cnj.jus.br/ 


\section{A COLABORAÇÃO NOS QUATRO ESTADOS}

Os scores médios para o conjunto das estratégias por estado são apresentados na tabela abaixo (Tabela 1). Como pode ser observado, Rio Grande do Sul e Rio de Janeiro são os estados com as iniciativas mais colaborativas, com as maiores médias e medianas. O Rio de Janeiro, contudo, ocupa uma primeira posição clara. Isso ocorre especialmente em razão do desenho e da dinâmica do NAT de seu estado e da CRLS. Santa Catarina está muito próxima do Rio Grande do Sul - perde posição porque não dispõe de uma iniciativa pré-processual de resolução administrativa via defensoria, como todos os demais estados mantêm. São Paulo se apresenta com a menos colaborativa das iniciativas, mas com um desvio-padrão mais alto, o que indica que há muita variação entre os scores médios de suas iniciativas - também é o estado com mais iniciativas.

\section{TABELA 1 SCORE FINAL POR ESTADO PARA TIPOS DE COLABORAÇÃO E SUAS MEDIDAS DE TENDÊNCIA CENTRAL E VARIAÇÃO}

\begin{tabular}{cccccc} 
Estado & Média & Mediana & Desvio Padrão & $\begin{array}{c}\text { Número } \\
\text { Atores }\end{array}$ & Resultado_Scores \\
\hline SP & 1,510 & 1,571 & 0,742 & 3,8 & Cooperação-Coordenação \\
SC & 1,821 & 1,643 & 0,513 & 5 & Cooperação-Coordenação \\
RS & 1,857 & 1,714 & 0,495 & 6 & Cooperação-Coordenação \\
RJ & 2,143 & 2,429 & 0,670 & 5,4 & Coordenação-Colaboração \\
\hline
\end{tabular}

*Os scores para cada estratégia individual constam do anexo eletrônico (cf. nota 3). Fonte: Elaborada pela autora.

\subsection{Compartilhamento de Informações}

O Gráfico 1 destrincha esses scores em cada uma das 7 dimensões. Como se pode observar, a pontuação de todas as iniciativas é mais alta no critério "compartilhamento de informações". De acordo com as entrevistas, essa é a principal forma de colaboração entre organizações.

A judicialização da saúde é vista pela maior parte dos/as entrevistados/as como um problema que só pode ser resolvido com base em evidências técnicas mais bem comunicadas entre as organizações envolvidas. Assim, o acesso e o compartilhamento de sistemas é especialmente relevante nas parcerias. Isso é potencializado pelo volume e pelo ritmo da judicialização, caracterizado pela frequência dos pedidos de tutela de urgência, por prazos curtos e decisões cujo descumprimento se dá sob pena de multa diária ou bloqueio do orçamento da pasta.

Os mecanismos de comunicação informal - como e-mails, telefone e aplicativos de mensagens, são vias importantes a que todos os atores envolvidos na judicialização recorrem constantemente. Elas não substituem, no entanto, o acesso a sistemas eletrônicos oficiais que estabelecem a organização e o fluxo de trabalho entre os órgãos (tais como S-Codes em São Paulo, AME no Rio Grande do Sul, Siscomaj em Santa Catarina ou PGE-Net em todos os estados). O Rio Grande do Sul é o estado que 
mais investe nesse tipo de compartilhamento. O estado cedeu acesso ao seu sistema interno AME a todos os atores da judicialização, menos a advogados/as.

São Paulo, por outro lado, talvez tenha desenvolvido o sistema mais cobiçado pelas secretarias, o S-Codes, que, além de organizar em linha industrial as respostas a ações judiciais, coleta informações sobre o fenômeno e gera relatórios e indicadores que permitem a atuação estratégica da secretaria (Naffah, Chieffi \& Correa, 2010; Toma, Soares, Siqueira \& Domingues, 2017). Esse sistema, contudo, só é compartilhado entre PGE e SES no estado. Em Santa Catarina, o Siscomaj-Ceos no âmbito do NAT, gerido pela SES mas utilizado e compartilhado com todo o sistema de justiça, também eleva a pontuação do estado nesse quesito.

\section{GRÁFICO 1 MÉDIAS POR ESTADO DA PONTUAÇÃO PARA CADA DIMENSÃO DE COLABORAÇÃO}

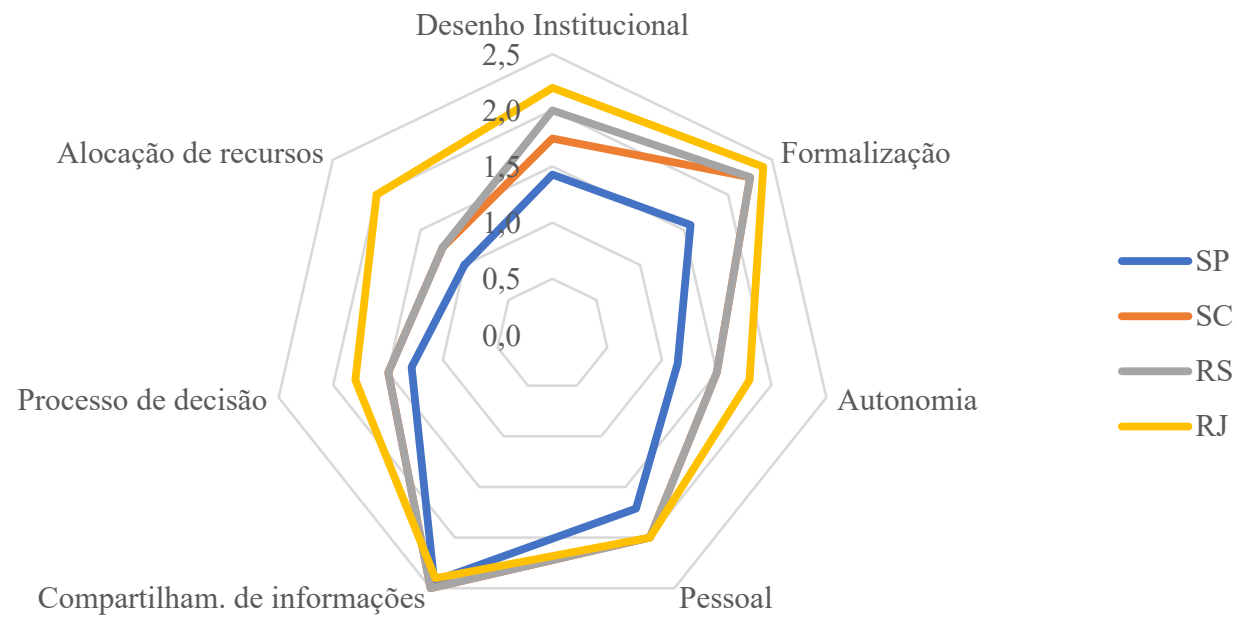

*Os scores para cada estratégia individual constam do anexo eletrônico (cf. nota 3).

Fonte: Elaborado pela autora.

\subsection{Alocação de Recursos}

Na dimensão "alocação de recursos", o Rio de Janeiro destoa dos demais estados. Isso se explica tanto pela experiência da CRLS quanto pelo próprio NAT - nelas, há alocação clara a pactuada de recursos e pessoal entre Justiça e SES. Para os demais estados, a baixa pontuação nessa dimensão permite discutir como a alocação de recursos para estratégias de enfrentamento da judicialização é suportada por cada ator e, talvez desproporcionalmente, pela administração pública.

\subsection{Formalização}

Em relação ao requisito "formalização", apenas 4 das estratégias atingem score 3, pois partem de termos de cooperação ou convênios formalmente assinados pelos órgãos envolvidos e de arranjos informais em curso, de acordo com as entrevistas. São elas: os Comitês Estaduais no Rio de Janeiro, 
no Rio Grande do Sul e em Santa Catarina - à época da coleta de dados, o comitê paulista havia sido formalizado em termo, mas apenas iniciava suas atividades -, além da CRLS. Um exemplo de arranjo informal que intensifica a colaboração é o caso narrado pela magistrada entrevistada no Rio de Janeiro: um grupo de WhatsApp em que os/as membros/as não só trocam informações gerais, mas discutem medidas concretas para casos judiciais em curso. A não ser pelo processo administrativo paulista (score 0) e pela iniciativa informal do "casamento institucional (score 1), todas as demais estratégias têm termo de formalização.

\subsection{Autonomia}

Para a dimensão "autonomia", os comitês estaduais receberam score 3. Esses comitês se tornaram estruturas relativamente autônomas em relação às organizações que os compõem - mesmo que haja algum desequilíbrio de poderes e função entre elas, já que os comitês funcionam dentro do Judiciário e, em tese, são instituições de iniciativa do CNJ. A CRLS recebeu pontuação 2, pois, apesar de surgir da parceria entre PGE e SES, com atuação das defensorias e do SMS-Rio de Janeiro, ainda consta como uma estrutura da SES, da qual depende a maior parte de sua atividade - ou seja, a palavra final é da SES, não obstante as decisões serem deliberadas. O mesmo ocorre para o NAT do Rio de Janeiro, que, a despeito de relativa autonomia, se submete à coordenação do assessor-chefe da assessoria técnica da Subsecretaria Jurídica da SES do Rio de Janeiro. Todas as demais estratégias recebem nota 1. Nelas, as organizações atuam de forma independente e autônoma - tomam decisões sobre o tema, e a parceria não assume, ela mesma, autonomia em relação às atividades individuais dos parceiros.

\subsection{Desenho Institucional}

Em desenho institucional, poucas iniciativas se organizam ao redor de entes próprios. Assim, os 4 comitês receberam nota 3 nessa dimensão, assim como a CRSL e o NAT fluminense - dispõem de espaço físico próprio, organização hierárquica que coordena as atividades, distribuição de papéis e competências claras. O Acessa SUS, o Ser Saúde, a parceria entre SES, PGE e TJRS para cumprimento de decisões e os NATs paulista e catarinense receberam nota 2 - partem de documentos formais de organização, como vimos no critério de formalização, mas são estratégias que dependem de um dos entes quase exclusivamente - no caso, o TJSP para o NAT paulista e a administração pública para as demais. Esse ente firma convênios não onerosos com os parceiros para que ele possa prestar o serviço de triagem ou consultoria. Todas as demais iniciativas recebem nota 1.

\subsection{Processo de Decisão}

Os comitês recebem score 3 para processo de decisão, pois, ainda que haja desequilíbrio de poder entre as organizações que compõem tais parcerias, a tomada de decisão é de fato coletiva - as recomendações e os enunciados são tirados das deliberações entre membros/as, de modo que as diferentes organizações buscam convencer umas às outras ou fazem concessões. A CRLS, o Acessa SUS e o NAT fluminense recebem 2. Há debate conjunto das organizações sobre as iniciativas, mas uma das organizações assume centralidade e a palavra final - no caso, a SES. Todas as demais parcerias recebem nota 1 por serem de processos de decisão não deliberativos entre as organizações, ainda que haja troca de informação. Por exemplo, a PGE traça estratégias de defesa em comunicação com a SES, mas decide sozinha como conduzirá o processo. 


\subsection{Pessoal}

Por fim, nenhuma das estratégias envolve pessoal-chave dos níveis mais hierarquicamente superiores que poderiam crivelmente estabelecer compromissos em nome de sua instituição ou decidir por ela. À exceção do processo administrativo paulista, que não compõe uma parceria, todas as 19 iniciativas pontuam 2, pois envolvem atores de médio escalão em suas organizações, no caso da SES, ou juízes/ as e membros/as do sistema de justiça indicados pelos/as presidentes dos tribunais ou dirigentes das organizações. Nesse caso, em razão da autonomia funcional dos servidores/as dessas entidades, aqueles/as que são indicados dificilmente podem dizer representar suas instituições no sentido de tomar decisões por elas.

A Tabela 2 apresenta os scores médios por estratégia. A pontuação média de São Paulo para todos os critérios e seu desvio-padrão podem ser explicados por 2 fatores. O primeiro é o conjunto maior de estratégias de gestão da judicialização nesse estado do que nos demais. Além do Comitê Estadual de Saúde e do NAT, São Paulo ainda dispõe de 2 sistemas administrativos de gestão processual: o Acessa SUS e o processo administrativo comum, que pontua 0 por ser uma estratégia que envolve apenas a SES. O segundo é a aposta numa parceria próxima e cooperativa entre a PGE e a SES como estratégia predominante. Como discutido acima, trata-se de uma parceria que, para além do processo judicial, se organiza especialmente por mecanismos informais de cooperação, como o casamento institucional.

\section{TABELA 2 SCORES POR ESTRATÉGIA POR ESTADO}

\begin{tabular}{|c|c|c|c|c|c|c|c|c|}
\hline \multirow{2}{*}{ Estratégia } & \multicolumn{2}{|c|}{ SP } & \multicolumn{2}{|c|}{ RJ } & \multicolumn{2}{|c|}{ RS } & \multicolumn{2}{|c|}{ SC } \\
\hline & Média & Mediana & Média & Mediana & Média & Mediana & Média & Mediana \\
\hline Atendimento administrativo & 0 & 0 & & & & & & \\
\hline SER Saúde & & & & & 1,714 & 2 & & \\
\hline CRLS & & & 2,571 & 3 & & & & \\
\hline Acessa SUS & 1,857 & 2 & & & & & & \\
\hline Cumprimento & 1,571 & 1 & 1,429 & 1 & 1,714 & 2 & 1,429 & 1 \\
\hline Defesa judicial & 1,571 & 1 & 1,429 & 1 & 1,429 & 1 & 1,571 & 1 \\
\hline Comitê Estadual & 2,492 & 2 & 2,571 & 3 & 2,571 & 3 & 2,571 & 3 \\
\hline "Casamento institucional" & 1,429 & 1 & & & & & & \\
\hline NAT & 1,714 & 2 & 2,429 & 2 & & & 1,714 & 2 \\
\hline
\end{tabular}

Fonte: Elaborada pela autora.

O Rio de Janeiro destoa como o estado com a maior média. Esse resultado é causado, principalmente, pela combinação da Câmara de Resolução de Litígio em Saúde com a presença de um Comitê Estadual ativo e de um NAT que integra justiça e administração pública diretamente. Ou seja, mais da metade das iniciativas fluminenses envolvem mais de 3 atores em parceria nas 3 frentes de enfretamento da judicialização: pré-processual, processual e metaprocessual. Ademais, tais iniciativas são desenhadas 
de forma a se destacarem da ação individual de seus atores ou de articulações que se comportam apenas como troca de informação, ou seja, ganham institucionalidade própria.

A média alta do Rio Grande do Sul não é causada por uma estratégia pré-processual, mais modesta que a CRLS, e sim, sobretudo, pela pontuação do seu Comitê Estadual. Um dos primeiros comitês criados no Brasil, segundo os/as entrevistados/as, trata-se de um espaço bastante colaborativo, criado especificamente para a governança da judicialização no estado.

Por fim, Santa Catarina tem média de colaboração maior que a de São Paulo, mas, considerando a variação e o número de iniciativas, tem o menor número de iniciativas integrativas, além de ser o único estado a não contar com uma iniciativa de saneamento administrativo em parceria com a Defensoria Pública.

\section{DISCUSSÃ0}

Os resultados da pesquisa demonstram que existe, em geral, convergência entre os estados analisados em relação às respostas institucionais à judicialização e aos padrões de colaboração. As diferenças, contudo, são relevantes porque conferem pistas a estudos futuros sobre como explicar o surgimento e a durabilidade dessas colaborações ou mesmo seu impacto sobre a judicialização da saúde.

\subsection{Fortalecimento do Processo Administrativo e Parcerias com a Defensoria Pública}

Em 3 dos 4 estados há algum procedimento anterior à judicialização que visa dirimir conflitos de forma administrativa mediante parcerias com a Defensoria Pública. A aposta no fortalecimento da via administrativa como meio de reduzir a judicialização tem sido documentada pela literatura tanto para a saúde (Silva, Petramale \& Elias, 2012; Teixeira, 2011; Wang, 2015) quanto para outras políticas públicas, como a previdência social (CNJ, 2020) e a educação infantil (Ximenes, Oliveira \& Silva, 2019).

Nos casos estudados, o perfil da representação judicial é essencial para que iniciativas como essa surjam. Santa Catarina, por exemplo, é o único dos 4 estados a não prever uma estratégia de enfrentamento administrativo da judicialização. A maior parte das ações judiciais no estado advém da advocacia privada (Pereira, Santos, Nascimento \& Schenkel, 2010; Vilvert, Buendgens, Campos \& Oliveira, 2019), sendo a Defensoria Pública uma entidade ainda em construção (Moreira, 2019). São Paulo tem um perfil semelhante - a maior parte da judicialização do estado é representada pela advocacia privada, mas a Defensoria Pública é uma entidade mais antiga e estabelecida do que em Santa Catarina (Moreira, 2019) e tem se tornado um ator relevante em termos de número de ações judiciais em saúde (TCU, 2017).

Para os 2 estados, contudo, parcerias e trabalho conjunto entre a PGE e a SES se apresentam como estratégias mais alinhadas com o perfil da judicialização local. A atuação conjunta das 2 entidades pode qualificar as defesas judiciais no grande volume de casos que advêm da advocacia privada. Ademais, mesmo a possibilidade de trazer esses casos para o processo administrativo das secretarias somente ocorreria com a ação judicial já em curso.

No Rio de Janeiro e no Rio Grande do Sul, ao contrário, a judicialização é altamente dependente da atuação da defensoria pública (Pepe et al., 2010; Travassos et al., 2013). Isso torna a CRLS e a parceria da SES-RS com a Defensoria Pública estadual ferramentas de gestão da judicialização desejáveis e potencialmente bastante efetivas. A administração pública pode se alinhar com apenas 
uma organização - em vez de centenas de advogados/as privados/as) -, que representa a porta de entrada da maior parte das ações judiciais, e converter essas demandas em requisições administrativas antes mesmo de serem judicializadas.

\subsection{Especialização}

Outro ponto comum em todas as iniciativas é a especialização das procuradorias e das secretarias em departamentos específicos para a defesa e o cumprimento de decisões judiciais. Tal como em outras políticas, como a previdência social (CNJ, 2020), o volume de ações judiciais e os riscos de sanções por descumprimento exigem respostas rápidas e efetivas da administração pública. Isso incentiva a especialização dos setores administrativos que recebem essas ações ou elaboram suas defesas, assim como torna a assessoria jurídica das secretarias um ator-chave que pondera os riscos de interferência do sistema de justiça em cada etapa do ciclo de políticas públicas.

A especialização, em especial em relação à defesa judicial, concretiza uma demanda por tradução da linguagem da política pública para a linguagem do processo judicial. Como a literatura já destacou inúmeras vezes, a principal crítica à atuação judicial sobre a política de saúde é a de decidir de forma não técnica, ignorando decisões especializadas já tomadas pela burocracia estatal (Wang et al., 2020). Essa falta de deferência geraria consequências não desejáveis à política, como a alocação ineficiente e potencialmente regressiva de recursos públicos (Chieffi \& Barata, 2009; Ferraz, 2011; Wang, 2015). Assim, a gestão e sua defesa processual se especializariam para traduzir essa linguagem técnica e os dilemas alocativos que ela performa para a linguagem do processo, tornando-a compreensiva aos atores do sistema de justiça.

Essa especialização, contudo, também pode ser vista como um efeito alocativo potencialmente ineficiente causado pela judicialização. Os setores especializados recebem recursos humanos e financeiros para lidar com demandas judiciais em saúde, enquanto tais recursos poderiam ser destinados às atividades-fim das secretarias.

\subsection{A Atuação do Conselho Nacional de Justiça}

Outro ponto comum são as iniciativas ligadas à atuação do CNJ desde 2009: os Comitês Estaduais de Saúde e NATs. O CNJ pode ser considerado um dos atores mais relevantes na promoção de redes de articulação entre administração pública e sistema de justiça, especialmente o Judiciário (CNJ, 2019; Vasconcelos, 2020; Wang, 2015).

Após a audiência pública da saúde no STF em 2009, o CNJ tem desenvolvido um trabalho de intensa construção de uma verdadeira esfera paralela de discussão e decisão em saúde, por meio do Fórum da Saúde, do Comitê Executivo Nacional e dos Comitês Estaduais (Tullii, 2017). Hoje, a criação de NATs e comitês é imposta pelo próprio $\mathrm{CNJ}$ aos tribunais estaduais e federais em todos os estados, o que fortaleceu o movimento por maior colaboração (Vasconcelos, 2020).

Restam dúvidas, porém, sobre a efetividade dessas iniciativas, considerando que, se sua constituição é imposta à justiça, a participação dos demais atores é voluntária. Ademais, recomendações e resoluções que decorrem desses fóruns não precisam ser seguidas por juízes/as estaduais ou federais, uma vez que se trata de um órgão não jurisdicional. Tampouco os NATs são de consulta obrigatória por magistrados/as (Ventura, 2012). O que as entrevistas e a literatura sugerem, entretanto, é que, 
sobretudo no ambiente dos comitês, questões que começam a ser trazidas à justiça podem ser ventiladas à administração, permitindo que esta eventualmente se antecipe e utilize a judicialização como um indicativo de gargalos da política de saúde que merecem correção (Vasconcelos, 2018, 2020).

\subsection{Mais Atores, Mais Colaboração?}

Os resultados da pesquisa apontam que, quanto mais atores numa iniciativa, mais colaborativa é aquela estratégia. As iniciativas mais colaborativas em todos os estados - Acessa SUS, CRLS e Comitês estaduais - são também as iniciativas com maior número de atores (confira o Anexo eletrônico). Enquanto isso, o estado menos colaborativo, São Paulo, é também o que envolve, em média, o menor número de organizações por estratégia - uma média de 3,8, enquanto os demais têm, em média, entre 5 e 6 organizações envolvidas por iniciativa (Tabela 1).

Esse resultado é particularmente contraintuitivo. Seria de se esperar que, quanto maior o número de organizações envolvidas numa estratégia, maiores os custos de transação de uma colaboração e, portanto, menores as chances de ela ocorrer. As literaturas sobre judicialização da política e colaboração interorganizacional, no entanto, oferecem pistas para o que pode estar por trás de tais resultados.

Em primeiro lugar, é provável que as iniciativas mais colaborativas envolvam mais atores, porque refletem a própria natureza do problema da judicialização de políticas públicas: a pluralidade de atores envolvidos, da administração pública e do sistema de justiça (Da Ros, 2014; Lima \& Vasconcelos, 2019) e a atuação interdependente entre eles para compor a judicialização. A judicialização da saúde, como qualquer judicialização de políticas públicas, não é causada só pela atuação de juízes/as e tribunais; também depende de quem aciona o sistema de justiça e da atuação da administração pública que dá causa a essas demandas judiciais, de forma consciente ou não. Ou seja, todos os atores são potenciais pontos de veto interdependentes (Ansell \& Gash, 2008; Bryson, Crosby \& Stone, 2006) sobre a judicialização da política de saúde, de modo que é lógico que iniciativas que procurem endereçar o fenômeno também busquem trazer todos esses atores de veto à mesa.

Uma segunda explicação pode estar na distribuição de custos e benefícios das colaborações estudadas. Para os atores do sistema de justiça, os custos para participar de parcerias como comitês, CRLS e Acessa SUS são relativamente baixos, enquanto os ganhos são potencialmente altos (Ansell \& Gash, 2008). Ou seja, para quase todos os atores do sistema de justiça, participar dessas estratégias não altera de forma significativa o desempenho normal de suas atividades, mas pode resultar numa redução substantiva da sua carga de trabalho. Se essas estratégias forem bem-sucedidas, defensorias proporiam menos ações judiciais e juízes/as teriam menor volume de trabalho relativo a casos em saúde.

Isso também explica por que é menos provável ver a advocacia privada representada nesses fóruns. ${ }^{9}$ Os custos para alinhar a atuação de todos/as os/as advogados/as sobre o tema são muito altos - ou mesmo impeditivos, considerando que entidades de classe, como a Ordem dos Advogados do Brasil (OAB), não têm o poder de controlar a atuação da carreira -, e os benefícios seriam negativos para a categoria, que perderia clientes ou teria honorários bastante reduzidos se apenas atuasse na esfera administrativa.

De outro lado, os atores da administração pública (e de procuradorias) incorrem em quase todos os custos de colaboração para a CRLS e o Acessa SUS - desde estabelecer e monitorar os fluxos de

\footnotetext{
${ }^{9}$ Em entrevista, uma juíza federal do Rio de Janeiro destacou que a $\mathrm{OAB}$ era frequentemente chamada a compor as reuniões do comitê estadual, mas que não participava dos encontros.
} 
trabalho entre todas as organizações, desenvolver e disponibilizar sistemas de informação, até custear e gerir a própria estrutura física que organiza essas parcerias. Mas os benefícios são potencialmente percebidos como maiores do que os custos - menos gastos com compras não licitadas de medicamentos fora das listas e protocolos clínicos do SUS, menos multas ou bloqueios judiciais de recursos.

No caso de comitês estaduais e NATs, existem alguns custos organizacionais alocados à justiça. Mas há também mais benefícios ao Judiciário, que, por exemplo, pode contar com assessoramento técnico prévio em casos difíceis, bem como atuar de forma mais geral sobre a política de saúde com a composição dos comitês - ou seja, maior ingerência e poder sobre temas e problemas tipicamente não judiciais. ${ }^{10}$

Por fim, é provável que todas as organizações envolvidas percebam a colaboração como algo benéfico. Os atores entrevistados frequentemente destacam os espaços de colaboração, como os comitês, como lugares úteis a diálogo e articulação entre organizações da administração pública e do sistema de justiça. Das entrevistas, é possível inferir uma mudança de mentalidade que passa a associar mais benefícios à colaboração para enfrentar a judicialização da saúde do que ao modelo adversarial até então vigente (Da Ros, 2014).

\section{CONCLUSÃO}

A judicialização da saúde se apresenta como uma realidade para a política pública de saúde como um todo há quase 20 anos. Segundo dados atuais (CNJ, 2019), não há indícios de que deixará de existir no médio prazo. O fenômeno cria incentivos para a colaboração. Trata-se de problema complexo e policêntrico, que envolve uma pluralidade de organizações e para o qual uma solução não poderia ser concebida ou implementada com a atuação unilateral de um único órgão.

Isso não quer dizer que a colaboração seja o santo graal, que deve ser perseguido a todo custo para enfrentar a judicialização (Bryson et al., 2006; Peters, 1998). Como se pode depreender dos casos estudados, o perfil da judicialização importa, e nem sempre se articular com mais atores é uma opção viável ou desejável.

Este estudo é um primeiro esforço de mapeamento e análise dessas estratégias e abre uma agenda de pesquisa que une a literatura sobre judicialização de políticas públicas com a literatura sobre colaboração interorganizacional. Os próximos passos para compreender a judicialização da saúde precisam se voltar tanto a explicar a formação específica de cada uma dessas colaborações por estado quanto a determinar seus efeitos sobre o fenômeno e a política de saúde como um todo.

Mesmo sem se debruçar sobre causas e efeitos dessas colaborações, o presente trabalho avança a literatura de judicialização de políticas públicas ao desenvolver um estudo comparado e dinâmico do fenômeno, que inclui sua pluralidade de atores. Este estudo também contribui para o fortalecimento de uma agenda de pesquisas sobre a judicialização da política que ocorre no ambiente subnacional. Ao aplicar a mesma metodologia de coleta e análise para 4 estados, propondo uma forma de mensuração da colaboração interorganizacional que pode ser replicada, mais trabalhos podem avançar o estudo de outras iniciativas estaduais e permitir, assim, uma melhor compreensão do fenômeno pelo Brasil.

\footnotetext{
${ }^{10} \mathrm{O}$ balanço entre custos e benefícios varia de iniciativa para iniciativa, mas, como vimos, é, em geral, desproporcionalmente suportado pela administração pública, o que pode comprometer, no longo prazo, a estabilidade dessas colaborações (Ansell \& Gash, 2008; Bryson et al., 2006).
} 


\section{REFERÊNCIAS}

Ansell, C., \& Gash, A. (2008). Collaborative governance in theory and practice. Journal of public administration research and theory, 18(4), 543-571.

Arantes, R. B., \& Moreira, T. M. Q. (2019). Democracia, instituições de controle e justiça sob a ótica do pluralismo estatal. Opinião Pública, 25(1), 97-135.

Biehl, J., Amon, J. J., Socal, M. P., \& Petryna, A. (2012). Between the court and the clinic: lawsuits for medicines and the right to health in Brazil. Health Hum Rights, 14(1), E36-52.

Bryson, J. M., Crosby, B. C., \& Stone, M. M. (2006). The design and implementation of Cross-Sector collaborations: Propositions from the literature. Public administration review, 66, 44-55.

Caetano, C. R. (2017). Webpalestra: Judicialização de medicamentos (Vídeo). Florianópolis, SC: Telessaúde. Recuperado de https://repositorio.ufsc. br/xmlui/handle/123456789/181555

Chagas, V. O., Provin, M. P., Guimarães, M. P., \& Amaral, R.G (2020). Institutional strategies as a mechanism to rationalize the negative effects of the judicialization of access to medicine in Brazil. BMC Health Serv Res, 20(80), 1-14.

Chieffi, A. L., \& Barata, R. B. (2009). Judicialização da política pública de assistência farmacêutica e equidade. Cadernos de Saúde Pública, 25(8), 18391849.

Conselho Nacional de Justiça. (2019). Judicialização da saúde no Brasil: perfil das demandas, causas e propostas de solução. Brasília, DF: Autor.

Conselho Nacional de Justiça. (2020). A judicialização de benefícios previdenciários e assistenciais. Brasília, DF: Autor.

Da Ros, L. (2014). Mayors in the Dock: Judicial Responses to Local Corruption in Brazil (Tese de Doutorado). University of Illinois at Chicago, Chicago, Illinois.

Da Ros, L., \& Ingram, M. C. (2019). Power, activation, decision making, and impact: subnational judicial politics in Brazil. In S. M. Sterett, \& L. D. Walker (Eds.), Research Handbook on Law and Courts. Cheltenham, UK: Edward Elgar Publishing.
Dye, T. R. (2013) Understanding public policy: Pearson new international edition. Tallahassee, Florida: Pearson Higher Ed.

Fanti, F. (2010). Políticas de saúde em juízo: um estudo sobre o município de São Paulo (Dissertação de Mestrado). Universidade de São Paulo, São Paulo, SP.

Ferraz, O. M. (2011). Health inequalities, rights and courts: The social impact of the judicialization of health. In A. E. Yamin, \& S. Gloppen (Eds.), Litigating health rights: Can courts bring more justice to health. Cambridge, MA: Harvard University Press.

Gray, B. (1985). Conditions facilitating interorganizational collaboration. Human Relations, 38(10), 911-936.

Guimarães, R. C. M., \& Palheiro, P. H. D. (2015). Medidas adotadas para enfrentar a judicialização na secretaria de saúde do Estado do Rio De Janeiro e a experiência da Câmara de Resolução de Litígios de Saúde. In Conselho Nacional dos Secretários de Saúde (Org.), Direito à saúde - para entender a gestão do SUS. Brasília, DF: Conass.

Howlett, M., Ramesh, M., \& Perl, A. (2009). Studying public policy: Policy cycles and policy subsystems, 3. Oxford, UK: Oxford University Press.

Kapiszewski, D., \& Taylor M. M. (2013) Compliance: conceptualizing, measuring, and explaining adherence to judicial rulings. Law \& Social Inquiry, 38(4), 803-835.

Keast, R., Brown, K., \& Mandell, M. P. (2007). Getting the right mix: Unpacking integration meanings and strategies. International Public Management Journal, 10(1), 9-33.

Kerche, F. (2007). Autonomia e discricionariedade do Ministério Público no Brasil. Dados, 50(2), 259279.

King, G., Keohane, R. O., \& Verba, S. (1994). Designing social inquiry: Scientific inference in qualitative research. Princeton, NJ: Princeton University Press.

Langford, M., Rodríguez-Garavito, C., \& Rossi, J. (2017). Social rights judgments and the politics of compliance: Making it stick. Cambridge, UK: Cambridge University Press.

Lima, R. B., \& Vasconcelos, N. P. (2019). O sistema de Justiça brasileiro: atores, atuação e consequências 
do arranjo constitucional. In N. M. Naffah Filho \& A. P. Souza (Orgs.), A carta. São Paulo, SP: Todavia.

Mahoney, J., \& Goertz, G. (2006). A tale of two cultures: Contrasting quantitative and qualitative research. Political Analysis, 14(3), 227-249.

McNamara, M. (2012). Starting to untangle the web of cooperation, coordination, and collaboration: A framework for public managers. International Journal of Public Administration, 35(6), 389-401.

McNamara, M. (2016). Unraveling the characteristics of mandated collaboration. Advancing collaboration theory: Models, typologies, and evidence. In J. C. Morris, K. Miller-Stevens (Eds.), Advancing collaboration theory: Models, typologies, and evidence. London, UK: Routledge.

Moreira, T. M. Q. (2019). Disputas institucionais e interesses corporativos no Sistema de Justiça: impasses na criação da Defensoria Pública nos estados. Dados, 62(4), e20170071.

Morris, J. C., \& Miller-Stevens, K. (2016). Advancing collaboration theory: Models, typologies, and evidence. London, UK: Routledge.

Naffah, M. N., Filho, Chieffi, A. L., \& Correa, M. C. (2010). S-Codes: um novo sistema de informações sobre ações judiciais da Secretaria de Estado da Saúde de São Paulo. Bepa, 7(84), 18-30.

Onwuegbuzie, A. J., \& Leech, N. L. (2005). On becoming a pragmatic researcher: The importance of combining quantitative and qualitative research methodologies. International Journal of Social Research Methodology, 8(5), 375-387.

Peixoto, F. (2017). O impacto (custos) das ordens judiciais no orçamento público da saúde (Apresentação de slides). Rio de Janeiro, RJ: Secretaria de Saúde do Estado do Rio de Janeiro. Recuperado de http:// slideplayer.com.br/slide/8624997/

Pepe, V. L. E., Ventura, M., Sant'ana, J. M. B., Figueiredo, T. A., Souza, V. R., Simas, L., ... Osorio-deCastro, C. G. S. (2010). Caracterização de demandas judiciais de fornecimento de medicamentos "essenciais" no estado do Rio de Janeiro, Brasil. Cadernos de Saúde Pública, 26(3), 461-471.

Pereira, J. R., Santos, R. I. D., Nascimento, J. M. D. N., Jr., \& Schenkel, E. P. (2010). Análise das demandas judiciais para o fornecimento de medicamentos pela
Secretaria de Estado da Saúde de Santa Catarina nos anos de 2003 e 2004. Ciência \& Saúde Coletiva, 15, 3551-3560.

Peters, G. (1998, Summer). Managing horizontal government - The politics of coordination. Public Administration, 76, 295-311.

Ramos, E. M. B., Diniz, I. M., \& Madureira, A. S. (2015). O Conselho Nacional de Justiça: o Fórum da Saúde e o excesso de judicialização. Cadernos Ibero-Americanos de Direito Sanitário, 4(4), 81-89.

Silva, H. P., Petramale, C. A., \& Elias, F. T. (2012). Avanços e desafios da política nacional de gestão de tecnologias em saúde. Revista de Saúde Pública, 46, 83-90.

Souza, A. M. (2016). A atuação em rede de instituições governamentais na resolução de conflitos sobre demandas sanitárias no Rio de Janeiro (Dissertação de Mestrado). Fundação Getulio Vargas, Rio de Janeiro, RJ.

Souza, T. G. (2018). A judicialização residual da saúde e sua relação com o desempenho dos serviços públicos de saúde e a efetividade do direito à saúde em dois municípios do estado do Rio de Janeiro (Tese de Doutorado). Fundação Oswaldo Cruz, Escola Nacional de Saúde Pública Sergio Arouca, Rio de Janeiro, RJ.

Teixeira, M. F. (2011). Criando alternativas ao processo de judicialização da saúde: o sistema de pedido administrativo, uma iniciativa pioneira do estado e município do Rio de Janeiro (Dissertação de Mestrado). Fundação Oswaldo Cruz, Escola Nacional de Saúde Pública Sergio Arouca, Rio de Janeiro, RJ.

Toma, T. S., Soares, A. C., Siqueira, P. S. F, \& Domingues, R. (2017). Estratégias para lidar com as ações judiciais de medicamentos no estado de São Paulo. Cadernos Ibero-Americanos de Direitos Sanitários, 6(1), 35-54.

Travassos, D. V., Ferreira, R. C., Vargas, A. M. D., Moura, R. N. V. D., Conceição, E. M. D. A., Marques, D. D. F., ... Ferreira, E. F. (2013). Judicialização da Saúde: um estudo de caso de três tribunais brasileiros. Ciência \&Saúde Coletiva, 18, 3419-3429.

Tribunal de Contas da União. (2017). Acórdão 1787/2017. Plenário, Processo /009.253/2015-7, Sessão 16/8/2017, Brasília, DF. 
Tullii, M. S. (2017). Para além da judicialização: política pública da justiça no campo da saúde (Tese de Doutorado). Universidade de São Paulo, São Paulo, SP.

Vasconcelos, N. P. (2018). Mandado de segurança ou Ministério da Saúde? Gestores, procuradores e respostas institucionais à judicialização (Tese de Doutorado). Universidade de São Paulo, São Paulo, SP.

Vasconcelos, N. P. (2020). Solução do problema ou problema da Solução? STF, CNJ e a judicialização da saúde. REI - Revista Estudos Institucionais, 6(1), 83-108.

Ventura, M. (2012). O processo decisório judicial $e$ a assessoria técnica: a argumentação jurídica e médico-sanitária na garantia do direito à assistência terapêutica no Sistema Único de Saúde (Tese de Doutorado). Fundação Oswaldo Cruz, Escola Nacional de Saúde Pública Sergio Arouca, Rio de Janeiro, RJ.

Vilvert, S. H., Buendgens, F. B., Campos, O. H., Neto, \& Oliveira, H. A., Jr. (2019). Perfil das ações judiciais em assistência à saúde com bloqueio de verbas públicas no estado de Santa Catarina. Cadernos Ibero-Americanos de Direito Sanitário, 8(4), 119-144.

Wang, D. W. L. (2015). Right to health litigation in Brazil: The problem and the Institutional Responses. Human Rights Law Review, 15(4), 617-641.

Wang, D. W. L., Vasconcelos, N. P., Poirier, M. J., Chieffi, A., Mônaco, C., Sritharan, L., ... Hoffman, S. (2020). Health Technology Assessment and judicial deference to priority-setting decisions in healthcare: quasi-experimental analysis of right-to-health litigation in Brazil. Social Science \& Medicine, 265, 113401.

Williams, A. P. (2016). The development of collaboration theory: Typologies and systems approaches. In J. C. Morris, \& K. Miller-Stevens (Eds.), Advancing collaboration theory: Models, typologies, and evidence. London, UK: Routledge.

Ximenes, S. B., Oliveira, V. E., \& Silva, M. P. (2019). Judicialização da educação infantil: efeitos da interação entre o sistema de justiça e a administração pública. Revista Brasileira de Ciência Política, 29, 155-188.

\section{Natalia Pires de Vasconcelos}

https://orcid.org/0000-0002-0309-6904

Doutora em Direito pela Universidade de São Paulo; Professora assistente do Insper; Senior research fellow no Solomon Center for Health Law and Policy, Yale Law School. E-mail: nataliapv1@insper.edu.br 


\section{ANEXO}

\section{QUADRO 6 ENTREVISTADOS POR ESTADO, ÓRGÃOS, CARGOS E FORMAÇÃO}

\begin{tabular}{|c|c|c|c|c|}
\hline \multicolumn{5}{|c|}{ Rio de Janeiro } \\
\hline ESTADO & ORGAO & CARGO & CONTATO & FORMAÇÃO \\
\hline RJ & PGE-RJ & Procurador da PG-16 & presencial & formação jurídica \\
\hline RJ & JUD/NAT & $\begin{array}{c}\text { Juíza Federal titular de uma vara especializado } \\
\text { em matéria de saúde; Coordenadora do } \\
\text { Comitê Estadual da Saúde do CNJ do RJ }\end{array}$ & presencial & formação jurídica \\
\hline RJ & SESDEC-RJ & Consultor Jurídico da SESDEC-RJ & presencial & formação jurídica \\
\hline RJ & SESDEC-RJ & Coordenador do NAT-JUS RJ & presencial & farmacêutico \\
\hline RJ & SESDEC-RJ & Coordenadora da CRLS & presencial e telefônico & enfermeira \\
\hline RJ & PGE-RJ & $\begin{array}{c}\text { Procurador Chefe da PG16, especializada em } \\
\text { saúde }\end{array}$ & presencial & formação jurídica \\
\hline RJ & $\begin{array}{l}\text { CADJ/SESDEC- } \\
\quad \text { RJ }\end{array}$ & $\begin{array}{c}\text { Coordenadora da CADJ (Central de Atendimento } \\
\text { de Demandas Judiciais), SESDEC-RJ }\end{array}$ & presencial e telefônico & formação jurídica \\
\hline \multicolumn{5}{|c|}{ Rio Grande do Sul } \\
\hline ESTADO & ORGAO & CARGO & CONTATO & FORMAÇÃO \\
\hline $\mathrm{RS}$ & PGE-RS & $\begin{array}{l}\text { Membro do Conselho Superior da } \\
\text { Procuradoria-Geral do Estado, antigo } \\
\text { procurador do NARAS-RS, Capital }\end{array}$ & telefônico & formação jurídica \\
\hline RS & SES-RS & Coordenador da Assessoria Jurídica da SES-RS & telefônico & formação jurídica \\
\hline $\mathrm{RS}$ & PGE-RS & Procuradoria do Interior em saúde & telefônico & formação jurídica \\
\hline $\mathrm{RS}$ & PGE-RS & $\begin{array}{l}\text { Procurador da PGE-RS, um dos } \\
\text { coordenadores do Projeto +Saúde }\end{array}$ & telefônico & formação jurídica \\
\hline $\mathrm{RS}$ & SES-RS & $\begin{array}{l}\text { Coordenadora Adjunta da Coordenação de } \\
\text { Política da Assistência Farmacêutica (CPAF) }\end{array}$ & presencial e telefônico & farmacêutica \\
\hline
\end{tabular}


RAP | Entre justiça e gestão: colaboração interinstitucional na judicialização da saúde

\begin{tabular}{|c|c|c|c|c|}
\hline \multicolumn{5}{|c|}{ Santa Catarina } \\
\hline ESTADO & ORGAO & CARGO & CONTATO & FORMAÇÃO \\
\hline SC & SES-SC (COJUR) & Assistente técnica COJUR-SES/SC & presencial & formação jurídica \\
\hline SC & $\begin{array}{l}\text { SES-SC } \\
\text { (COMAJ) }\end{array}$ & Coordenador COMAJ até 2017 - SES/SC & presencial & formação jurídica \\
\hline SC & PGE-SC & Ex-consultor jurídico SES/SC até junho de 2017 & presencial & formação jurídica \\
\hline SC & SES-SC & Servidora da COMAJ, equipe técnica & presencial e telefônico & nutricionista \\
\hline SC & SES-SC & Diretora de Assistência Farmacêutica & presencial & farmacêutica \\
\hline SC & MP-SC & $\begin{array}{c}\text { Coordenadora-Adjunta do Centro de Apoio } \\
\text { Operacional dos Direitos Humanos e Terceiro } \\
\text { Setor, MP-SC }\end{array}$ & presencial & formação jurídica \\
\hline SC & SES-SC & Servidora da COMAJ, equipe técnica & presencial e telefônico & farmacêutica \\
\hline SC & PGE-SC & $\begin{array}{l}\text { Procurador-Chefe da PGE-SC, Criciúma, } \\
\text { NARAS Criciúma }\end{array}$ & telefônico & formação jurídica \\
\hline $\mathrm{SC}$ & PGE-SC & Procuradora integrante do NARAS & telefônico & formação jurídica \\
\hline \multicolumn{5}{|c|}{ São Paulo } \\
\hline ESTADO & ORGAO & CARGO & CONTATO & FORMAÇÃO \\
\hline $\mathrm{SP}$ & SES-SP & Ex-coordenadora da CODES & presencial & farmacêutica \\
\hline SP & PGE-SP & Procurador chefe da PJ8, PGE/SP & presencial & formação jurídica \\
\hline SP & CODES-SESSP & Coordenadora da CODES-SES/SP & presencial & enfermeira com jurídica \\
\hline SP & CODES-SESSP & Diretor Técnico da CODES-SES/SP & presencial & farmacêutico \\
\hline $\mathrm{SP}$ & CODES-SESSP & Assessor técnico - CODES/SES-SP & presencial & médico \\
\hline SP & PGE-SP & Procurador da PJ8 - especializada em saúde & presencial & formação jurídica \\
\hline
\end{tabular}

Fonte: Elaborado pela autora. 


\section{QUADRO 7 ROTEIRO DE ENTREVISTAS SEMIESTRUTURADAS}

\section{ROTEIRO DE ENTREVISTAS SEMIESTRUTURADAS}

* Perguntas indicativas: o roteiro poderá ser adaptado de acordo com o órgão de origem do/a entrevistado/a.

\section{Sobre o/a entrevistado/a}

1. Qual o cargo você ocupa? Há quanto tempo? 0 que você faz neste cargo?

2. Poderia nos contar um pouco da sua trajetória? Como você chegou no cargo que ocupa hoje?

3. Qual foi o seu primeiro contato com ações judiciais em saúde?

4. Qual a sua percepção sobre ações judiciais em saúde? As ações judiciais afetam seu trabalho? Como?

\section{Sobre os processos internos e fluxo de trabalho}

5. Como funciona o órgão em que você trabalha?

6. Você lida com processos administrativos ou judiciais em saúde? Se sim, como?

7. Como estes fluxos internos são organizados para responder a demandas judiciais? Poderia dar detalhes sobre estes caminhos e órgãos envolvidos?

8. Quais as respostas possíveis que do seu órgão à judicialização?

\section{Sobre as ações judiciais}

9. Poderia contar um pouco sobre as ações judiciais que o seu órgão recebe (se recebe)?

10. Em sua maioria, estas são ações individuais ou coletivas?

11. Quais os tratamentos mais requeridos? Eles fazem parte das listas do SUS ou dos protocolos clínicos?

12. Quais a doenças mais comuns nessas ações?

13. Seu órgão atua na execução das decisões judiciais? Se sim, como? Se não, quem atua?

14. Quais sanções são mais frequentemente aplicadas por juízes? Quais seus efeitos para o funcionamento do seu órgão?

15. 0 seu órgão enfrenta dificuldades em cumprir as decisões? Se sim, por quê?

\section{Interação interinstitucional}

16. 0 seu órgão interage com outros atores da administração pública? E do sistema de justiça?

17. Como ocorre essa interação?

18. Trata-se de interação formal ou informal? Ela ocorre no âmbito de alguma organização, comitê?

19. Existe alguma troca de informações periódica ou de sistemas entre estes órgãos?

Fonte: Elaborado pela autora. 